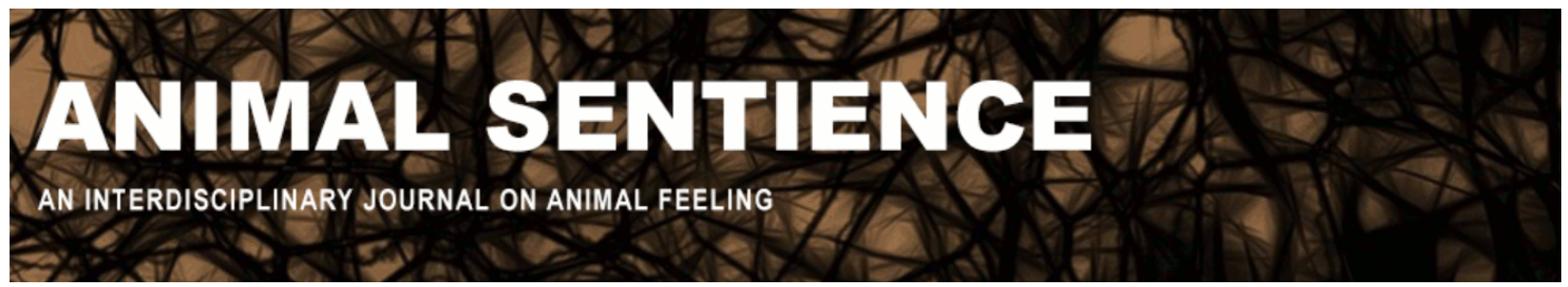

Bowers, Robert lan (2016) Devaluation as a strategy to address behaviourally whether fish feel. Animal Sentience 3(43)

DOI: $10.51291 / 2377-7478.1078$

Date of submission: 2016-01-13

Date of acceptance: 2016-01-30

(c)

This article has appeared in the journal Animal

Sentience, a peer-reviewed journal on animal

cognition and feeling. It has been made open access,

free for all, by WellBeing International and deposited

in the WBI Studies Repository. For more information,

please contact

wbisr-info@wellbeingintl.org.

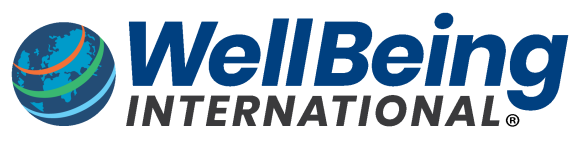

SOLUTIONS FOR PEOPLE, ANIMALS AND ENVIRONMENT 
Editorial Note: (1) This journal is devoted to the understanding of animal sentience, that is, feeling, not just "internal representations" - unless they are felt internal representations. Things can happen internally that are not felt. Insentient robots are capable of SS and SR learning. (2) This journal does not advocate performing painful experiments on animals. If the SS/SR devaluation experiments described here are deemed worthy of performing in order to cast light on the capacity of fish to feel anything at all, they should be just as informative with a positive SS/SR devaluation paradigm as with a negative one.

\title{
Devaluation as a strategy to address behaviourally whether fish feel
}

\author{
Commentary on Key on Fish Pain
}

\author{
Robert lan Bowers \\ Cognitive Science Program \\ Indiana University, Bloomington
}

\begin{abstract}
Failures of behavioural studies to address the question of whether fish feel pain have left scientists arguing on the basis of other criteria, including anatomy. I draw an analogy with a debate concerning the breadth of stimulus-response learning among nonhuman animals and propose an experiment that harks back to one solution to that debate: the devaluation paradigm. By changing the value of a noxious stimulus after training, one can differentiate a directly evoked response from a response to an intermediate representation, the pain.
\end{abstract}

Keywords: outcome devaluation, revaluation, stimulus-response (S-R), stimulus-stimulus (S-S), fish, pain, Pavlovian conditioning, instrumental conditioning

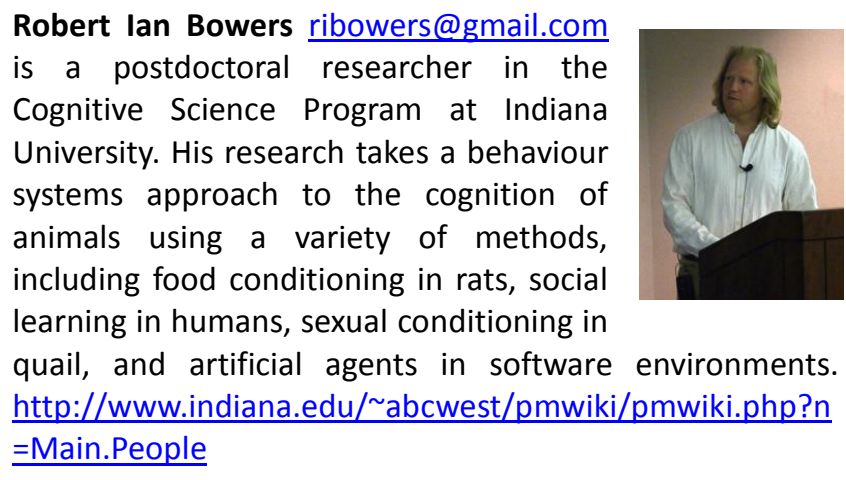

Key (2016) supposes contemporary understanding of pain to be at a level of maturity where one can identify whether an animal is "anatomically capable of feeling pain" (p. 1). Like other commentators, I find this unduly optimistic. The target article simultaneously exhibits undue pessimism regarding behavioural approaches. Though medically oriented approaches that simply quantify a fish's responses to the presentation of noxious stimuli do fail to address the question, knowledge of psychology research brings potential solutions that are worth considering.

In the context of this discussion, I want to remind the community of an empirical approach to an analogous debate that took place over the 1970s and 1980s. Before then, a common assumption was that learnt associations were direct links between stimulus and response, 
such that presentation of a conditional stimulus would directly evoke the conditional response, with no mediating representation required. All that is registered, in this case, is how to respond under specific stimulus circumstances. This is known as "stimulus-response" $(\mathrm{S}-\mathrm{R})$ learning. The alternative is stimulus-stimulus (S-S) learning, in which the animal learns an association between the conditional stimulus and the unconditional stimulus (US), such that the conditional stimulus would evoke, not the response per se, but a representation of the unconditional stimulus, which would thereupon bring about the conditional response. Before 1975, these might have seemed indistinguishable empirically, since, in either case, the stimulus is presented and the response observed. If the same is said after 1975, however, a reminder is in order of one viable solution, the US devaluation paradigm.

Before describing the devaluation experiment, I should establish the relevance of the S-R versus S-S learning debate to the current debate regarding pain in fish. Fish show clear avoidance responses to noxious stimuli. Given this starting point, the path to arguing that fish do not really feel pain is to suggest that the responses they show to noxious stimuli are reflexes that bypass any representational mediation. The stimulus might directly evoke the response. Alternatively, the stimulus may evoke pain, which in turn evokes the response. The no-pain hypothesis involves an S-R mechanism - the pain hypothesis, an S-S mechanism.

Let me acknowledge that a step remains between establishing the presence of internal representations and establishing the presence of feeling. How big this step is, and the specific relevance of representation to sentience, remain controversial. However, this is no reason to dismiss the proposed strategy. Evidence for or against the internal representation of noxious stimuli by fish may inform the apparently harder question of fish pain, for instance, by demonstrating the presence or absence of necessary or sufficient conditions, depending on the hypothesised relationship between representation and feeling. I assume only that the two notions are tightly related, such that addressing questions about representation with available empirical means is a step forward, even if clarity on how close this brings us to sentience awaits future methodological or theoretical developments.

In the past, S-R and S-S mechanisms have been differentiated by use of the US or outcome devaluation paradigm. A food reinforcer can be devalued with induced illness or satiation. If after Pavlovian (Holland \& Rescorla, 1975) or instrumental (Adams \& Dickinson, 1981) conditioning with food, the food is devalued, the subsequent conditional response will be attenuated. Such results suggest the presence of a representation of the US or outcome mediating stimulus and response. If what had been learnt was a direct stimulus-response association, devaluing the reinforcing stimulus should have had no impact on the conditional response.

These examples were conducted in food conditioning paradigms with rats. That rats feel pain is not doubted in the target article, nor is an opinion expressed regarding whether fish represent predictors of food. The important issues that arise specifically with fish and pain demand specific treatment. Note that S-R and S-S mechanisms can both occur in the same animal. Hence, the establishment of a S-R mechanism in one domain does not mean that the whole fish is a mindless $S-R$ machine incapable of subjective experience, just as the establishment of S-S learning does not imply that the animal relies on no S-R mechanisms elsewhere in its behavioural repertoire. With the force of decades of research and theory stressing the importance of recognising the specificity of learning (Domjan, 1997; Timberlake, 1990) in order to properly address the question about pain in particular, the 
experiment must be conducted within the domain in question. How an animal learns about food, sex, and pain cannot be assumed to be the same. A related complication is that "fish" refers to an enormous and highly diverse category of animals (Allen, 2013), among which nociception might vary as widely as it does throughout the rest of the vertebrates. If pigfish fail to show evidence of representing aversive stimuli, this is no assurance that horsefish will do the same, much less catfish, and much, much less dogfish. Is there a devaluation experiment that can establish whether lake trout represent pain?

The value of a noxious stimulus can be manipulated by repeated exposure (e.g., Polack et al., 2012), or by introducing anaesthetics in the water, or by competition with opposing motivational pressures (e.g., by presenting sexual stimuli to an animal ready to court). Train subjects to swim into an enclosure to avoid a noxious stimulus. (Alternatively, a response suppression measure could be used.) In a second phase, the noxious stimulus is reliably preceded by a splash of water in the tank. Then the devaluation of the noxious stimulus is applied in one group (and not in a control group). Will the conditional response to the splash now be attenuated relative to controls? If so, such results would suggest that the splash is not directly evoking the escape response, but rather that there is a representation of the aversive stimulus mediating the splash and the response. If the devaluation manipulation has no impact on the avoidance response of fish, one would have some ammunition for arguing against fish pain. A Pavlovian or instrumental conditioning procedure (or a mixture of both) could be used.

To claim that fish do not feel pain, given the availability of methods for beginning to address the question empirically, there is more experimental behavioural work to be done. No talk of default hypotheses or placing the onus on someone else will substitute for conducting the relevant experiments (cf. Morgan, 1903). Following the publication of the first devaluation studies, investigators found other ways of empirically addressing these questions that had earlier seemed beyond science (e.g., Holland \& Ross, 1981, found evidence of S-S learning by means other than devaluation ${ }^{1}$ ). Perhaps the same will be true of fish pain research, and all the faster if the important advances of our predecessors are remembered. In the meantime, strong claims about the presence or absence of pain in fish remain premature.

Author acknowledgement: I study neither fish nor pain, both important reservations.

\section{References}

Adams, C.D. \& Dickinson, A. (1981). Instrumental responding following reinforcer devaluation. Quarterly Journal of Experimental Psychology 33: 109-121.

Allen, C. (2013). Fish cognition and consciousness. Journal of Agricultural and Environmental Ethics 26: 25-39. doi:10.1007/s10806-011-9364-9

Domjan, M. (1997). Behavior Systems and the demise of equipotentiality: Historical antecedents and evidence from sexual conditioning. In M.E. Bouton, \& M.S. Fanselow

\footnotetext{
${ }^{1}$ Holland \& Ross (1981) showed that after serial compound conditioning with a light-tone-food sequence subsequent response to either tone or light was attenuated by presenting the other stimulus alone in an extinction phase. Both results suggest the presence of a stimulus-stimulus association between the tone and light mediating conditional response to either.
} 
(Eds.), Learning, motivation, and cognition: The functional behaviorism of Robert C. Bolles (pp. 31-51). Washington, DC: American Psychological Association. doi: 10.1037/10223002

Holland, P.C., \& Rescorla, R.A. (1975). The effect of two ways of devaluing the unconditioned stimulus after first- and second-order appetitive conditioning. Journal of Experimental Psychology: Animal Behavior Processes 1: 355-363. doi:10.1037/0097-7403.1.4.355

Holland, P.C., \& Ross, R.T. (1981). Within-compound associations in serial compound conditioning. Journal of Experimental Psychology: Animal Behavior Processes 7: 228-241. Key, B. (2016). Why fish do not feel pain. Animal Sentience 2016.003.

Morgan, C.L. (1903). An introduction to comparative psychology (Revised edition). London: Walter Scott.

Polack, C.W., McConnell, B.L., \& Miller, R.R. (2012). Associative foundation of causal learning in rats. Learning \& Behavior 41: 25-41. DOI 10.3758/s13420-012-0075-5

Timberlake, W. (1990). Natural learning in laboratory paradigms. In D.A. Dewsbury (Ed.), Contemporary issues in comparative psychology (pp. 31-54). Sunderland, MA: Sinauer Associates. doi: 10.1037/11525-002 